\title{
Review
}

\section{The role of impaired early insulin secretion in the pathogenesis of Type II diabetes mellitus}

\author{
R. E.Pratley, C. Weyer \\ Clinical Diabetes and Nutrition Section, National Institute of Diabetes, Digestive and Kidney Diseases, \\ National Institutes of Health, Phoenix, Arizona, USA
}

\section{Abstract}

Patients with Type II (non-insulin-dependent) diabetes mellitus manifest abnormalities in insulin action and insulin secretion. It is widely accepted that insulin resistance is an early finding, evident before the onset of hyperglycaemia and predictive of the subsequent development of diabetes. Whether abnormalities in insulin secretion also precede and predict diabetes has been debated. However, recent studies clearly indicate that early insulin secretion plays a critical role in maintaining normal glucose homeostasis. Crosssectional analyses show that acute insulin secretory responses (AIR) to intravenous glucose are lower in subjects with impaired glucose tolerance and those at high risk for developing diabetes. Prospectively, a low AIR predicts the development of diabetes in several populations. In longitudinal studies, AIR declines dramatically as patients progress from normal to impaired glucose tolerance and ultimately to diabetes. Early insulin secretion is important for the rapid and efficient suppression of endogenous glucose production after a meal. Thus, loss of early insulin secretion initially leads to post-prandial hyperglycaemia which, as the disease progresses, worsens to clinical hyperglycaemia. Strategies that enhance early insulin secretion improve glucose tolerance and represent a novel and more physiologic approach to improving glycaemic control in patients with Type II diabetes mellitus. [Diabetologia (2001) 44: 929-945]

Keywords Insulin action, insulin secretion, Type II diabetes mellitus, impaired glucose tolerance, pathogenesis.
Normal glucose tolerance is maintained by a precise balance between insulin secretion from pancreatic beta cells and insulin action on sensitive tissues, principally muscle, adipose tissue and liver [1,2]. Patients with Type II (non-insulin-dependent) diabetes mellitus manifest impairments in insulin secretion and insulin action and an increased rate of endogenous glucose production [1-3]. The relative importance of these abnormalities in the pathogenesis of the disease has been debated for many years. It is now generally

Received: 27 December 2000 and in revised form: 8 April 2001

Corresponding author: R. E. Pratley, Novartis Pharmaceuticals Corp., 59 Route 10, East Hanover, NJ 07936, USA

Abbreviations: AIR, acute insulin secretory responses; GLP-1, glucagon-like peptide receptor; HOMA- $\beta$ C, homeostatic model assessment of beta-cell function accepted that abnormalities in insulin secretion and insulin action contribute to the development of Type II diabetes, whereas the increase in endogenous glucose production is a later phenomenon. Insulin secretory dysfunction in Type II diabetes is both quantitative and qualitative [3-4]. In addition to a relative impairment in the amount of insulin released, the pattern of insulin secretion is abnormal. In this review, we focus on the critical role of impaired early insulin secretion in the pathogenesis of Type II diabetes.

Current understanding of the pathophysiology of Type II diabetes is based on the contributions of many laboratories working with different populations around the world. Since 1982, the National Institutes of Health has conducted a longitudinal study of the metabolic predictors of Type II diabetes in the Pima Indians of Arizona [5], a population uniquely suited for such studies because of their extraordinarily high 
incidence of the disease [6]. In this study, healthy adult subjects are admitted to the NIH Clinical Research Centre in Phoenix, Arizona for 10 to 14 days to undergo a series of tests including measurement of body composition (using either hydrodensitometry or dual-energy X-ray absorptiometry), glucose tolerance (75-g oral glucose tolerance test, OGTT), insulin secretion (25-g intravenous glucose tolerance test, IVGTT) and insulin action at physiological and supraphysiological insulin concentrations (2-step hyperinsulinaemic glucose clamp). Subjects are then followed longitudinally at approximately annual intervals. By the year 2000, over 500 individuals had participated in these detailed metabolic evaluations, many on several occasions over a number of years. Although the rate of Type II diabetes is much higher in the Pima Indians than in other populations, the pathogenesis of the disease in this group is, in most respects similar and therefore our conclusions are generally applicable to other groups.

\section{Physiology of normal insulin secretion}

A basic understanding of the physiology of normal insulin secretion is essential to defining and interpreting abnormalities of insulin secretion in people with diabetes. A detailed review of insulin secretory processes is beyond the scope of this article and is reported elsewhere $[4,7]$.

Insulin secretion is phasic: In vitro studies. Exposure of isolated pancreatic beta cells to glucose results in a phasic pattern of insulin secretion [7]. The initial response to glucose is characterized by a rapid increase in insulin secretion followed by a decline to near basal rates. This acute response, which lasts 1 to $3 \mathrm{~min}$, has been termed the rapid priming phase. Continued exposure of beta cells to glucose leads to a subsequent, slower second-phase of insulin secretion that can be maintained for several hours. A desensitization phase, characterized by sustained but lower insulin secretion can be demonstrated for up to 24 hours with prolonged exposure to glucose. The rapid initial phase of insulin secretion is believed to represent the release of insulin from mature secretory granules docked on, or in close proximity to, the beta-cell plasma membrane [8]. Subsequent phases of insulin secretion derive from stored secretory granules and, with prolonged exposure to glucose, de novo insulin synthesis.

Insulin secretion is phasic: In vivo studies. Phasic insulin secretion can also be demonstrated in vivo with the hyperglycaemic glucose clamp technique. This procedure uses a primed-variable intravenous infusion of glucose to produce a square wave of hyperglycaemia $[9,10]$. In non-diabetic subjects, this results in an immediate increase in the plasma insulin concentration, which peaks 3 to $5 \mathrm{~min}$ after the start of the infusion. Continued infusion of glucose leads to a second-phase of insulin secretion that can be sustained for several hours. Figure 1 depicts the typical biphasic pattern of insulin secretion in 17 healthy middle-aged and older men [10]. In this study, increasing plasma glucose concentrations by $7.9 \mathrm{mmol}$ above basal with the hyperglycaemic glucose clamp technique enabled clear delineation of first- and second-phase insulin secretory responses in vivo.

First-phase insulin secretion can be defined, therefore, as the rapid increase in insulin secretion that occurs immediately after exposure of beta cells to glucose and is completed within $10 \mathrm{~min}$. Second-phase insulin secretion is the subsequent sustained increase in insulin secretion beginning 10 to $20 \mathrm{~min}$ after exposure to glucose which can last for several hours.

Measuring insulin secretion. Although the hyperglycaemic glucose clamp technique provides precise measures of first- and second-phase insulin secretion, this method is time and labour intensive. Consequently, many investigators, particularly those doing large, epidemiologic studies involving hundreds of persons, have used alternative methods for estimating insulin secretion [5,11-20]. A number of studies, including those in Pima Indians, have measured first-phase insulin secretion in response to an intravenous glucose bolus [5,11-15]. The mean response to a 25-g intravenous glucose challenge, a dose that maximally stimulates insulin secretion, in 272 Pima Indians with normal glucose tolerance is illustrated in Figure 1B. As shown, peak insulin responses occur 3 to $5 \mathrm{~min}$ after the injection of glucose and decline thereafter. The acute insulin secretory response to glucose (AIR), an index of first-phase insulin secretion, is calculated as the mean incremental increase in plasma insulin concentration in samples obtained 3,4 , and 5 min after the glucose bolus [5].

Various estimates of insulin secretion have also been derived from insulin responses during oral glucose tolerance testing [16-20]. We recently examined the relation of several of these indices to the AIR [21]. The homeostatic model assessment of beta-cell function (HOMA- $\beta$ C) calculated from fasting plasma insulin $\left(\mathrm{I}_{0}\right)$ and glucose $\left(\mathrm{G}_{0}\right)$ concentrations $\left(\left[\mathrm{I}_{0} \times 20\right] /\right.$ $\left.\left[\mathrm{G}_{0}-3.5\right]\right)$ correlated modestly with the AIR in subjects with normal glucose tolerance $(r=0.29$, $p<0.01, n=245)$. But was less strongly related in those with impaired glucose tolerance $(r=0.16$, $p<0.05, n=153)$. Indices of insulin secretion derived from 120-min OGTT insulin $\left(\mathrm{I}_{120}\right)$ and glucose $\left(\mathrm{G}_{120}\right)$ responses were similarly related to the AIR in normal glucose tolerant subjects ( $r$ values $0.23-0.26, p<0.01$ ) and were more strongly related in those with impaired glucose tolerance ( $r$ values $0.26-0.39$, $p<0.01)$. Because indices derived from fasting insu- 

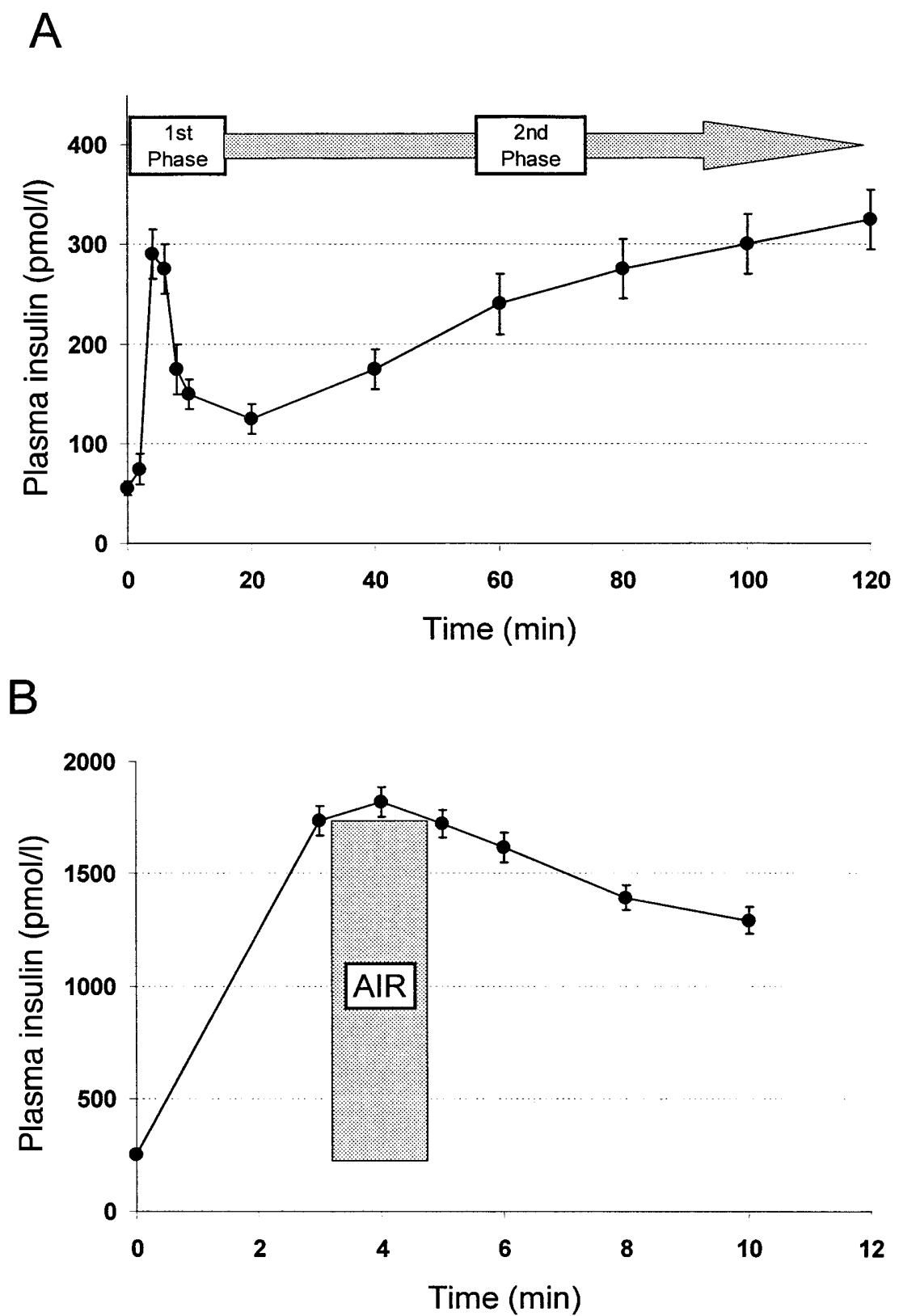

Fig.1. A Mean plasma insulin concentrations during a 2-h hyperglycaemic ( + $7.9 \mathrm{mmol} / \mathrm{l})$ glucose clamp in 17 middle-aged and older men. Distinct first-phase (0-10 min) and second phase (20-120 min) insulin secretory responses are evident. B Plasma insulin response to a 25 -g intravenous glucose bolus in 272 Pima Indians with normal glucose tolerance. The acute insulin secretory response (AIR, shaded box) is calculated as the mean increase in insulin concentration above basal in samples obtained 3, 4 and 5 min after the glucose bolus

lin and glucose concentrations primarily reflect basal rates of insulin secretion and indices derived from 2$\mathrm{h}$ responses primarily reflect second-phase insulin release, it is not surprising that the correlation of these measures with an index of first-phase insulin secretion, the AIR, is rather low.
To estimate early insulin secretion using oral glucose tolerance data, indices have been calculated using 30-min insulin $\left(\mathrm{I}_{30}\right)$ and glucose $\left(\mathrm{G}_{30}\right)$ responses. In Pima Indians, correlation coefficients between the insulin-to-glucose ratio $\left(\mathrm{I}_{30} / \mathrm{G}_{30}\right)$, the insulinogenic index $\left(\Delta \mathrm{I}_{30} / \Delta \mathrm{G}_{30}\right)$ and the corrected insulin response $\left(\left[\mathrm{I}_{30} / \mathrm{G}_{30}\right] \times\left[\mathrm{G}_{30}-70\right]\right)$ and the AIR ranged from 0.49 to $0.52(p<0.01)$ in subjects with normal glucose tolerance and 0.54 to $0.61(p<0.01)$ in subjects with impaired glucose tolerance. The relation between $\Delta \mathrm{I}_{30} / \Delta \mathrm{G}_{30}$ and AIR in patients with normal and impaired glucose tolerance is shown in Figure 2. We have also recently reported that the AIR is correlated to the $30 \mathrm{~min}$ incremental insulin response to a mixed meal $(r=0.28, p<0.01)[1]$. Although $\Delta \mathrm{I}_{30} /$ $\Delta \mathrm{G}_{30}$ and AIR are highly correlated in both groups, indices of early insulin secretion derived from the 

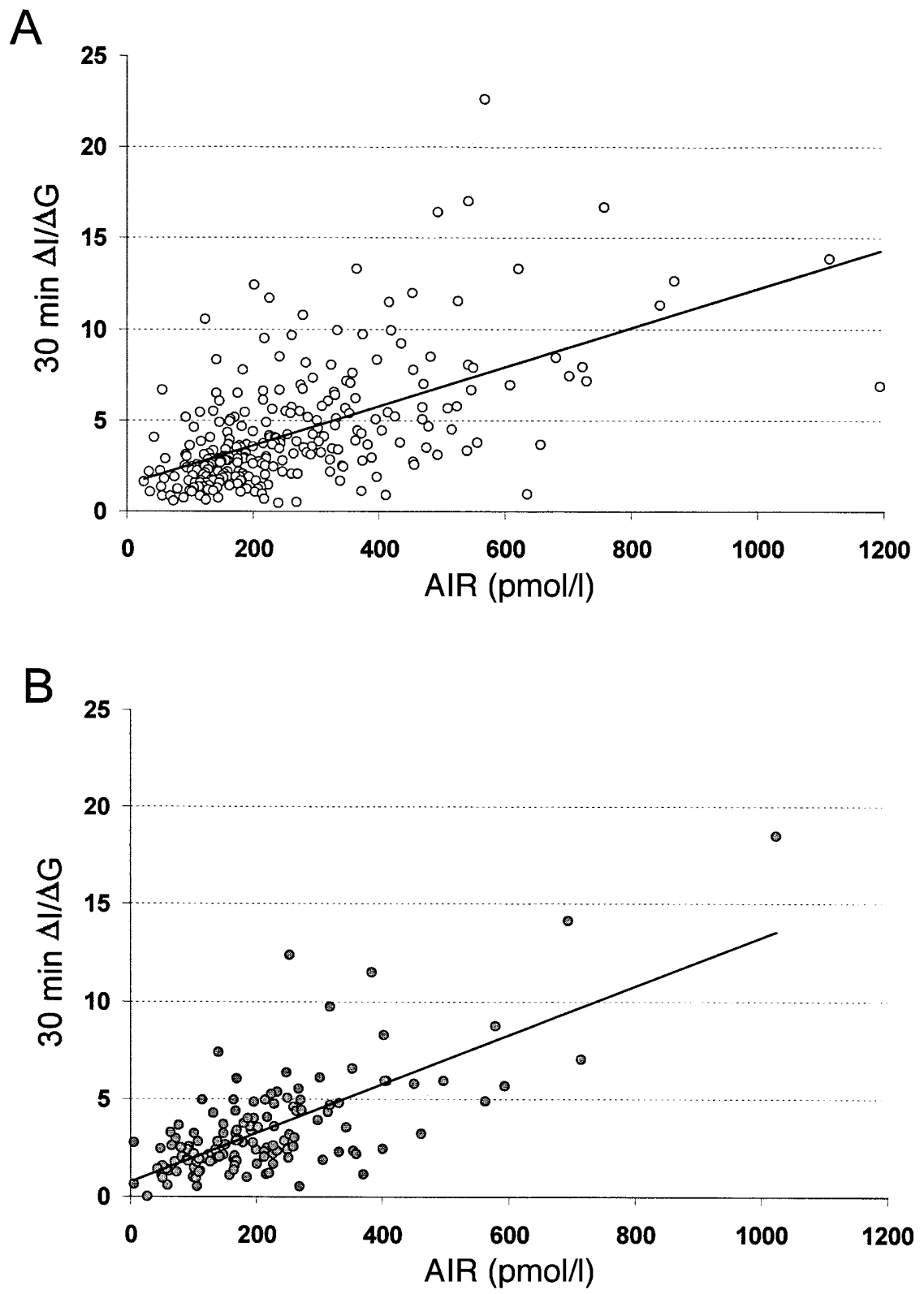

Fig. 2. Correlation between the insulinogenic index $\left(\Delta \mathrm{I}_{30} / \Delta \mathrm{G}_{30}\right)$ derived from $30 \mathrm{~min}$ insulin and glucose responses during a 75-g oral glucose tolerance test and the acute insulin response (AIR) to intravenous glucose in 272 Pima Indians with normal glucose tolerance $(r=0.45, p<0.0001)(\mathbf{A})$ and 166 Pima Indians with impaired glucose tolerance $(r=0.59, p<0.0001)(\mathbf{B})$

OGTT explain a minority of the variance (less than one third) in the AIR and there is a great deal of variability in these. Interindividual differences in rates of gastric emptying and incretin effects could affect responses to the OGTT and meal, but not the AIR, thereby contributing to some of the observed variability. In addition, it is likely that indices derived from 30-min insulin responses reflect contributions of both first- and second-phase insulin secretory pro- cesses. Thus, whereas these indices are better surrogate measures of the AIR than those obtained from either fasting or 2-h responses, they are not necessarily equivalent to first-phase insulin secretion. To distinguish true "first-phase secretion" (measured in vitro or in response to an intravenous glucose challenge) from indices derived from insulin responses during the first $30 \mathrm{~min}$ of an OGTT or meal test, the latter measures are usually referred to as "early" insulin responses.

\section{Early insulin secretion is important in maintaining normal glucose tolerance}

Because the AIR is measured in response to an unphysiologic beta-cell stimulus (an intravenous glucose bolus), the relevance of this measure to normal 
physiology has been questioned. The fact that the AIR is correlated to early insulin responses during a mixed meal or an OGTT supports, but does not prove the hypothesis that first-phase insulin secretion is physiologically relevant.

A better understanding of the role of early insulin secretion in normal physiology has come from experimental studies in which early insulin secretion has been manipulated. Early studies using a depancreatized dog model demonstrated that a prompt insulin response was essential for normal glucose tolerance [22]. In humans, a study used a brief intravenous infusion of somatostatin has been used to suppress early phase insulin secretion in healthy control subjects during intravenous and oral glucose tolerance tests [23]. Infusion of somatostatin $5 \mathrm{~min}$ before and 15 min after the injection of glucose blunted firstphase insulin secretion (from 0-10 min) during the IVGTT by $80 \%$, but did not affect second-phase insulin secretion. This selective loss of first-phase insulin secretion led to a worsening of intravenous glucose tolerance (calculated from the glucose disappearance curve) compared to control studies. A similar infusion of somatostatin $5 \mathrm{~min}$ before and $15 \mathrm{~min}$ after ingestion of an oral glucose load also largely abolished early insulin responses (from 0-30 min). At $30 \mathrm{~min}$, plasma insulin concentrations were less than a third of normal, but late insulin responses from 60 to 120 min were higher than in control studies without somatostatin. The ensuing loss of early insulin secretion, despite a hyperinsulinaemic secondphase response, markedly worsened oral glucose tolerance.

First-phase insulin secretion suppresses endogenous glucose production. To define the physiological role of first-phase insulin secretion in humans, the effects of loss of first-phase insulin secretion on glucose homeostasis during hyperglycaemic glucose clamps were studied [24]. Normal glucose tolerant subjects underwent 3 different studies; a control hyperglycaemic clamp in which glucose alone was infused, a second study in which glucose and somatostatin were infused and exogenous insulin was infused to mimic only the normal second-phase insulin response and a third study in which glucose and somatostatin were infused and exogenous insulin was infused to mimic first and second-phase insulin responses. Endogenous glucose production was suppressed by $90 \%$ within $20 \mathrm{~min}$ of the initiation of the glucose infusion in study 1 . In contrast, in study 2 , loss of first-phase insulin secretion was associated with a blunted suppression of endogenous glucose production. At $60 \mathrm{~min}$ endogenous glucose production was $50 \%$ of basal rate and even at $150 \mathrm{~min}$ it remained incompletely suppressed despite the infusion of exogenous insulin to mimic a normal second-phase insulin response. In study 3 , replacement of first and second-phase insulin responses with an exogenous insulin infusion suppressed endogenous glucose production to rates similar to those seen in the control study 1 .

In a similar set of experiments the temporal pattern, as well as the absolute increase in plasma insulin concentration, was shown to be important for the efficient suppression of endogenous glucose production in humans [25]. During hyperglycaemic glucose clamps, endogenous insulin secretion was suppressed with somatostatin and exogenous insulin was infused at a constant rate to increase plasma insulin to concentrations comparable to those achieved during a normal first-phase response, but without the typical biphasic pattern. Despite comparable plasma insulin concentrations, the absence of the normal biphasic pattern of insulin secretion was associated with impaired suppression of endogenous glucose production, which was less than half that observed in control hyperglycaemic glucose clamp studies (43\% vs $90 \%)$.

Early insulin secretion primes insulin sensitive tissues. In vivo, the effect of insulin to increase glucose uptake is delayed because insulin must traverse an endothelial barrier before binding to insulin receptors on sensitive tissues such as skeletal muscle and adipose tissue [26]. Investigators have suggested that an important function of early insulin secretion is to rapidly increase tissue (as opposed to plasma) insulin concentrations to overcome this barrier [27]. Using a catheterized dog model to measure insulin profiles in hind-limb lymph, they compared the effects of insulin infusions that mimicked a normal biphasic pattern of insulin secretion with infusions that mimicked only the second-phase insulin response. During the biphasic insulin infusion, lymph insulin quickly reached and maintained a steady state (within $10 \mathrm{~min}$ ), whereas during an insulin infusion that mimicked only second-phase secretion, a steady state was only achieved after 35 min and was lower than with the biphasic insulin infusion. In both experiments, the increase in tissue glucose uptake reflected the insulin profile in interstitial fluid (lymph) rather than the insulin profile in plasma, emphasizing the importance of the endothelial barrier in determining the time course of activation of insulin action.

Indirect effects of insulin to suppress endogenous glucose production. Insulin has rapid and direct effects on hepatocytes to inhibit glycogenolysis and gluconeogenesis in vitro. However, the time course for suppression of endogenous glucose production in vivo is unexpectedly slow, considering that insulin is secreted directly into the portal circulation and that hepatocytes lack an endothelial barrier. In fact, the pattern of suppression of endogenous glucose production closely parallels the action of insulin to suppress lipolysis $[28,29]$. This led to the suggestion that suppres- 


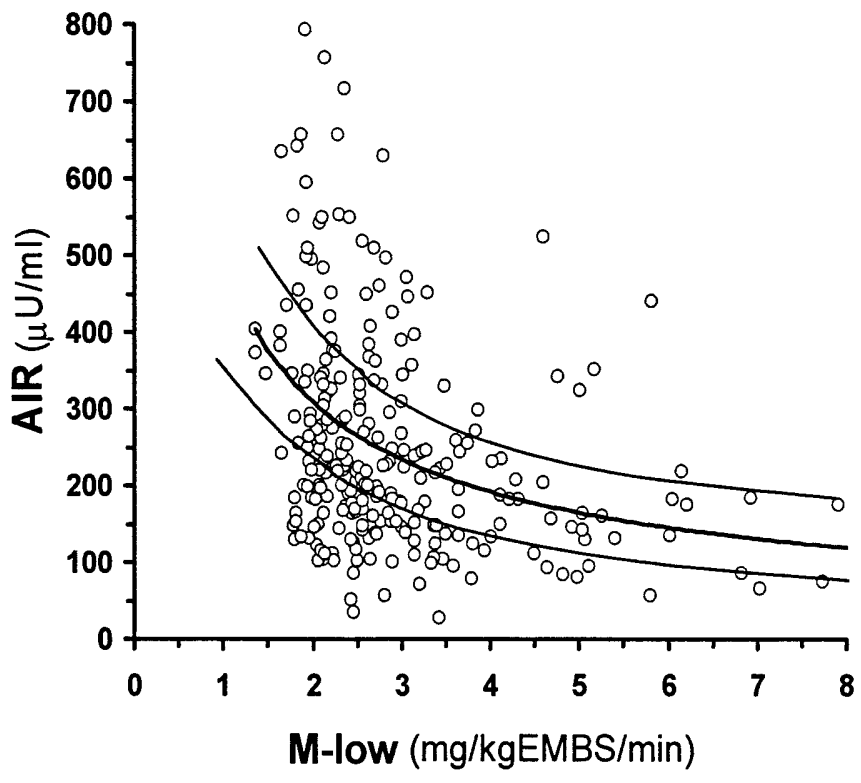

Fig.3. Hyperbolic relation between the acute insulin secretory response to a 25 -g intravenous glucose bolus (AIR) and insulin action (M-low) measured during a hyperinsulinaemic glucose clamp in 277 Pima Indians with normal glucose tolerance. The hyperbolic lines represent the predicted mean and $95^{\text {th }}$ percent confidence limits of the cross-sectional relation between the AIR and insulin action. EMBS = estimated metabolic body size

sion of endogenous glucose production by insulin predominately results from insulin's inhibition of lipolysis in adipose tissue, rather than by direct effects on hepatocytes [28]. The inhibition of lipolysis, in turn, decreases the delivery of non-esterified fatty acids to the liver, thereby inhibiting endogenous glucose production. This 'single gateway' hypothesis is supported by a number of experiments showing that the suppression of endogenous glucose production by insulin reflects decreases in plasma non-esterified fatty acids concentrations and can be prevented by infusion of lipid and heparin to maintain plasma freefatty acid concentrations at basal concentrations [27-29].

The central role of early insulin secretion. Collectively, these data suggest that early phase insulin secretion is an important mechanism to rapidly shift metabolic processes from the fasting to the prandial state. During fasting, tissue insulin concentrations are low, lipolysis and circulating non-esterified fatty acids are high, and the glucose requirements of the brain and other tissues are met through endogenous glucose production. The initial increase in plasma glucose upon ingestion of a meal stimulates a rapid increase in insulin secretion which serves to optimally increase interstitial insulin concentrations. The anti-lipolytic effect of insulin on adipocytes causes a rapid decrease in non-esterified fatty acids and inhibition of endoge- nous glucose production. The early insulin response could also prime insulin-sensitive tissues to increase the efficiency of glucose disposal. Within minutes, the metabolic state is efficiently shifted from glucose production toward glucose disposal.

\section{Insulin secretion is proportional to insulin action}

A requisite for normal glucose tolerance is that the amount of insulin secreted must be proportional to tissue insulin sensitivity. Fasting and 2-h OGTT insulin concentrations are negatively correlated with insulin action and are often used as surrogate measures of insulin resistance $[19,20]$. It is less widely appreciated that first-phase insulin secretion is also closely related to insulin action. A hyperbolic relation between the AIR and estimates of insulin sensitivity $\left(\mathrm{S}_{\mathrm{i}}\right)$ derived by mathematical modelling of the plasma glucose and insulin curves following a frequently sampled intravenous glucose tolerance test has been described [30]. A similar hyperbolic relation between AIR and insulin action measured during a hyperinsulinaemic euglycaemic clamp (the M-value) is evident in data from 277 Pima Indians with normal glucose tolerance (Fig.3). Thus, in cross-sectional analyses, acute insulin secretory responses increase with decreasing insulin action (lower M-values) and vice versa, to maintain normal glucose tolerance. The recognition that measures of insulin secretion need to be interpreted with respect to the underlying degree of insulin resistance has been critical to understanding the role of insulin secretory dysfunction in the pathogenesis of Type II diabetes. We and others [30] have calculated the best-fitting regression model relating insulin secretion and action in subjects with normal glucose tolerance and, as a tool to compare groups at high risk for diabetes and to visualize longitudinal changes, have plotted insulin secretion and insulin action in selected subgroups relative to this normative data.

\section{Cross-sectional studies: early insulin secretion is impaired in persons with impaired glucose homeostasis and those at high risk for diabetes}

Diabetes. Over 40 years ago, the pioneering studies of Yalow and Berson [31] showed that patients with Type II diabetes manifested abnormalities in early insulin secretion in response to an oral glucose challenge. Similar findings have been reported in many other groups $[2,32,33]$ and are evident in the Pima Indians, as well. Figure 4 shows plasma glucose (A) and insulin (B) responses to a 75-g OGTT in Pima Indians with normal glucose tolerance, impaired glucose tolerance and early diabetes. The total insulin response among patients with diabetes is quantita- 

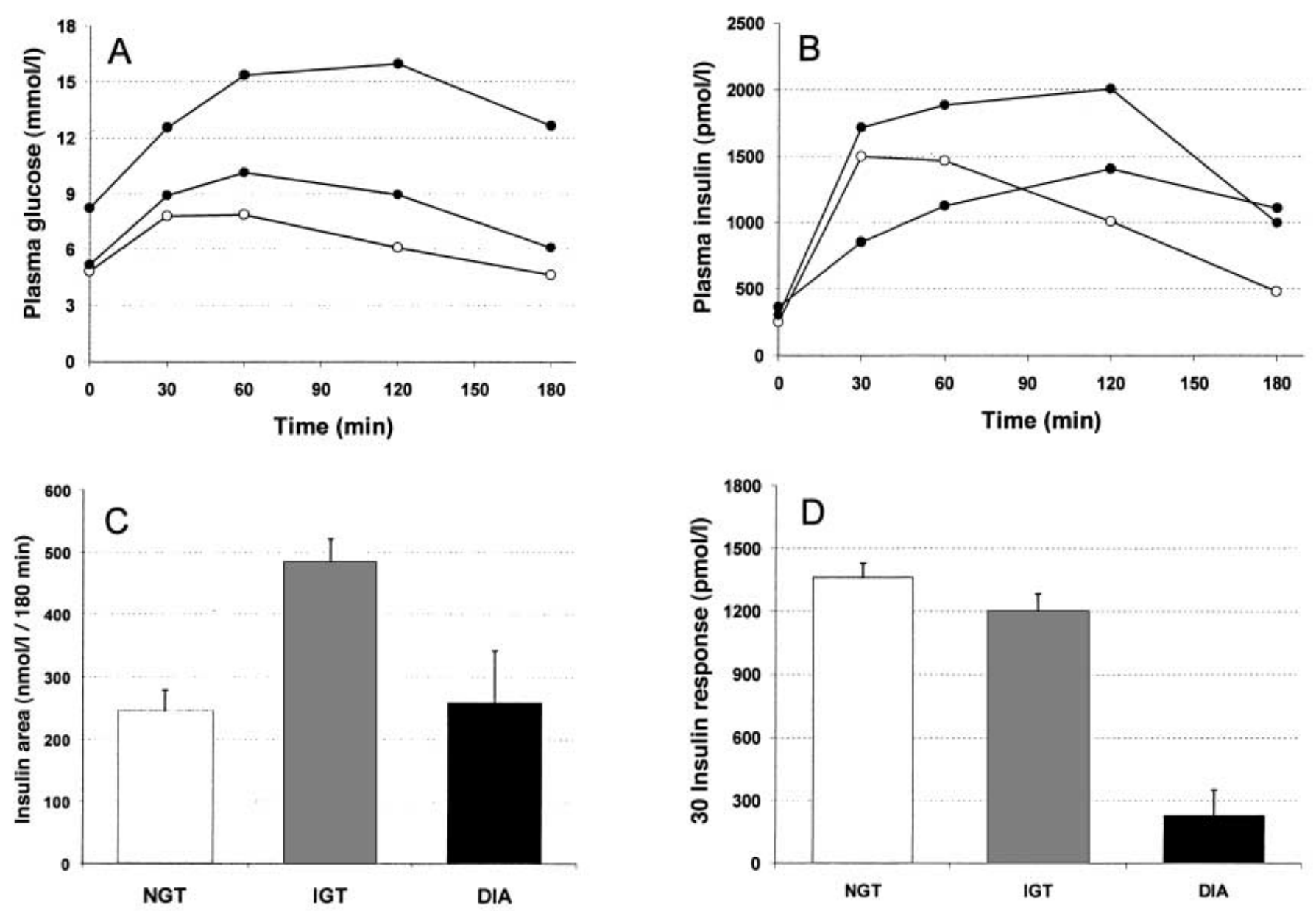

Fig. 4. Plasma glucose $(\mathbf{A})$ and insulin responses $(\mathbf{B})$ to a $75-\mathrm{g}$ oral glucose tolerance test in Pima Indians with normal glucose tolerance (NGT, $\bigcirc)$, impaired glucose tolerance (IGT, $\bigcirc)$ and diabetes (DIA, ). There were no significant differences between NGT and DIA in the insulin response above basal $(\mathbf{C})$, but responses were significantly higher $(p<0.0001)$ in those with IGT. The increment in $30 \mathrm{~min}$ insulin above basal (D) tended to be slightly lower $(p=0.15)$ in those with IGT than in those with NGT but were $80 \%$ lower $(p<0.0001)$ in those with diabetes. All values were adjusted for age, sex and \% body fat and, in addition, the $30 \mathrm{~min}$ response was adjusted for insulin action (M-low)

tively similar to that in patients with normal glucose tolerance [insulin area under the curve (258 vs 240 nmol/1/180 min)] (Fig. 4C). Relative to their degree of hyperglycaemia, however, persons with diabetes manifest an impairment in insulin secretion. Persons with impaired glucose tolerance, in contrast, secrete almost twice as much insulin (485 nmol/1/180 min, $p<0.0001)$ than those with normal glucose tolerance (Fig. 4C). More striking is the alteration in the temporal pattern of insulin secretion among patients with diabetes. Whereas subjects with normal and impaired glucose tolerance have brisk increases in insulin $30 \mathrm{~min}$ after the ingestion of glucose, those with dia-

betes on average manifest a blunted and delayed response (Fig. 4B) on average. Thus, the mean 30-min incremental insulin response among those with diabetes is less than $20 \%$ of the mean response in persons with normal glucose tolerance (Fig. 4D). Among persons with impaired glucose tolerance, this response also tends to be lower. A similar degree of impairment in early insulin secretion can be observed in response to a mixed meal challenge in persons with diabetes (data not shown).

The finding of low early (30 min) insulin responses to oral glucose and mixed meal challenges suggest that first-phase insulin secretion is impaired in those with diabetes. This is, in fact, the case. In 1967 a study showed that first-phase insulin responses to an intravenous glucose challenge were markedly lower in subjects with Type II diabetes [34]. This finding has subsequently been replicated in a number of studies [35-37]. Marked impairment in first-phase insulin secretory responses to intravenous glucose at a very early stage in the development of hyperglycaemia was shown and by the time fasting plasma glucose concentrations exceeded $6.4 \mathrm{mmol} / \mathrm{l}$, first-phase insulin responses were found mostly absent [35]. Similar findings are evident in Pima Indians (Fig.5). When the AIR is plotted as a function of fasting plasma glucose concentration it is apparent that very few per- 


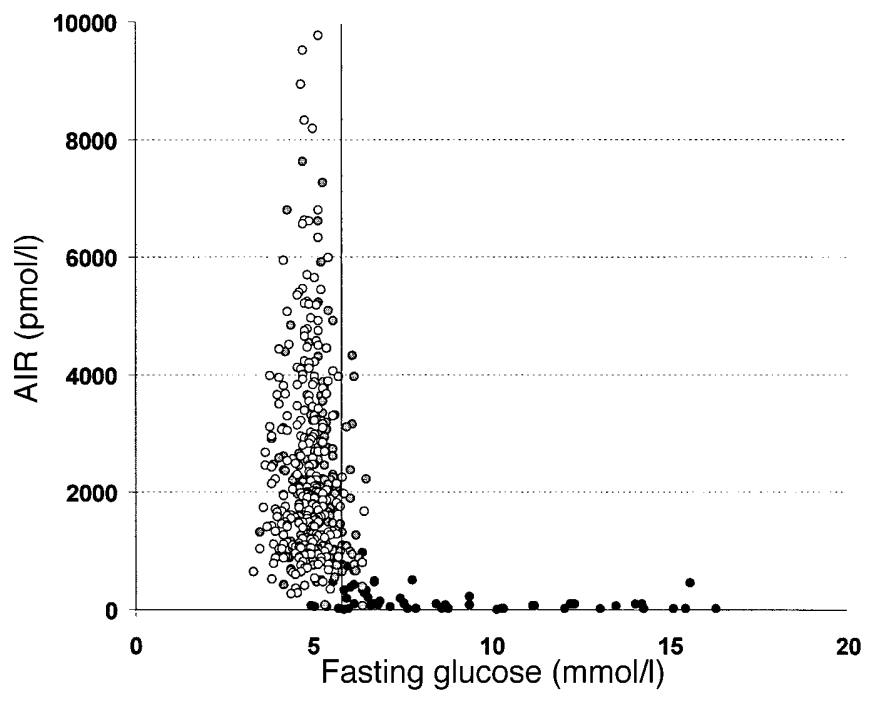

Fig. 5. Relation between the AIR and fasting plasma glucose concentration in Pima Indians with normal glucose tolerance $(\mathrm{NGT}, \mathrm{O})$, impaired glucose tolerance (IGT, $\bigcirc$ ) and diabetes (DIA, O) The vertical bar is set at a fasting plasma glucose concentration of $6.1 \mathrm{mmol} / \mathrm{l}$, corresponding to the definition of impaired fasting glucose

sons with a fasting plasma glucose concentration above $6.1 \mathrm{mmol} / \mathrm{l}$, the lower cutoff for the recently defined category of impaired fasting glucose [38], are able to mount even a minimal response to the intravenous glucose challenge.

Since early phase insulin secretion plays a key role in the normal suppression of endogenous glucose production in response to a meal, loss of the normal insulin secretory pattern could contribute to postprandial hyperglycaemia in patients with diabetes. Rates of endogenous glucose production (using tracer intravenous infusions of $\left[3-{ }^{3} \mathrm{H}\right]$-glucose) and glucose absorption (labelled with $\left[2-{ }^{3} \mathrm{H}\right]$-glucose) were measured in patients with diabetes and non-diabetic control subjects [39]. Both groups had comparable rates of absorption of glucose. In non-diabetic subjects, endogenous glucose production was promptly suppressed by more than $50 \%$ within 30 min of the meal. In contrast, in patients with diabetes, endogenous glucose production was approximately $50 \%$ higher at baseline and was not suppressed until 2 hours after ingestion of the meal. Thus, the hyperglycaemic response to a standard meal in patients with diabetes is attributable to inadequate suppression of endogenous glucose production resulting from impaired or absent early insulin secretion.

Impaired glucose tolerance. While it was widely acknowledged that persons with diabetes manifested an impairment in first-phase insulin secretion, there was, for many years, considerable controversy about whether this was also true in subjects with milder degrees of glucose intolerance. First-phase insulin se- cretion and early insulin responses have been reported to be lower in subjects with impaired glucose tolerance than in those with normal glucose tolerance in some studies [40-44], whereas other studies have found no differences or even higher responses in those with impaired glucose tolerance [45, 46]. Not all studies have adequately accounted for the underlying degree of insulin resistance, thus contributing to some of the disparities between studies. However, even after controlling for insulin resistance, it is apparent that first-phase insulin secretion is much more variable in those with impaired glucose tolerance, in contrast to the uniformly low acute insulin secretory responses among patients with diabetes. Some individuals with glucose intolerance have an AIR in the "normal range" (in absolute terms) while some lack a response altogether. Some of this heterogeneity could reflect inherent biological differences between subjects in cross-sectional studies. For example, a recent longitudinal study by our group showed that the AIR is lower in subjects with impaired glucose tolerance who progress to diabetes than in those who revert to normal glucose tolerance [47]. Heterogeneity in the selection of subjects based on their degree of hyperglycaemia also might have contributed to conflicting findings since the classification of glucose intolerance is somewhat arbitrary and does not reflect the continuous nature of defects in insulin secretion with increasing glucose concentrations [48]. We have recently shown that, on average, subjects with isolated impaired fasting glucose (fasting plasma glucose concentrations $6.1-7.0 \mathrm{mmol} / \mathrm{l}$ and 2 -h glucose concentrations $<7.8 \mathrm{mmol} / \mathrm{l}$ ) have more severe defects in first-phase insulin secretion than those with isolated impaired glucose tolerance (fasting plasma glucose concentrations $<6.1 \mathrm{mmol} / 1$ and 2-h glucose concentrations between $7.8-11.1 \mathrm{mmol} / \mathrm{l}$ ) [49]. This is depicted in Figure 6 in which the mean AIR is plotted as a function of the mean M-value for each group with glucose intolerance. Thus the defect in the AIR is more severe in those with higher fasting plasma glucose concentrations (Fig.5). Nevertheless, compared to the normal range (Fig.3), all groups with glucose intolerance manifest an impairment in insulin secretion relative to their greater degree of insulin resistance. These results illustrate the importance of considering the degree of underlying insulin resistance when evaluating the adequacy of insulin secretion and highlight the heterogeneity among groups with varying degrees of glucose intolerance.

Persons at high risk for Type II diabetes. Although cross-sectional studies clearly indicate that persons with diabetes and impaired glucose tolerance manifest impairments in insulin secretion and insulin action, it is not possible to ascertain from these studies whether the observed abnormalities are primary, con- 
A

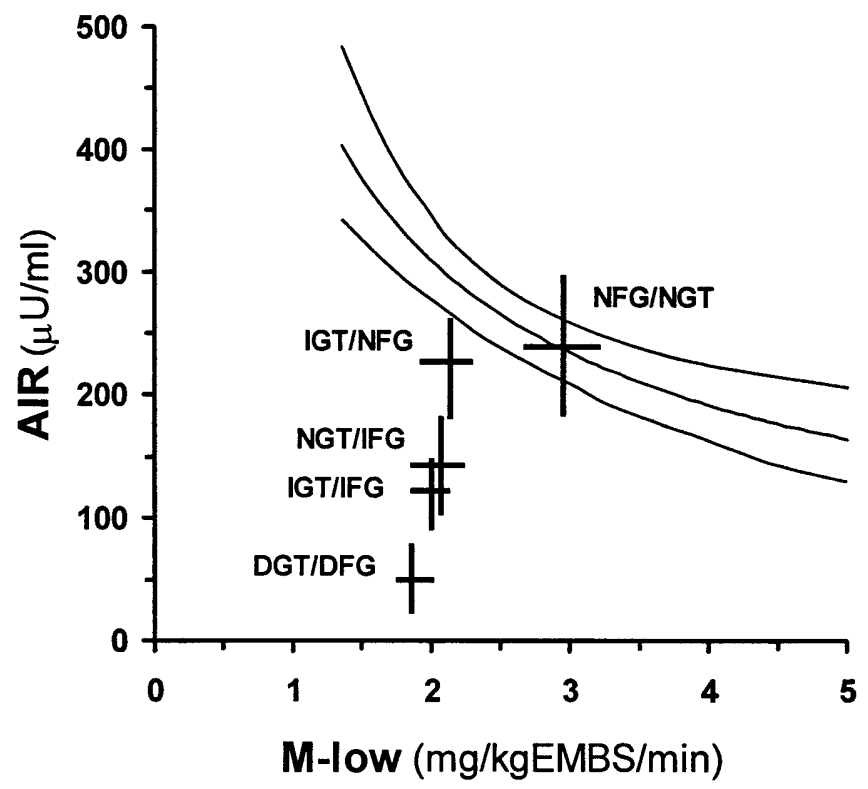

B

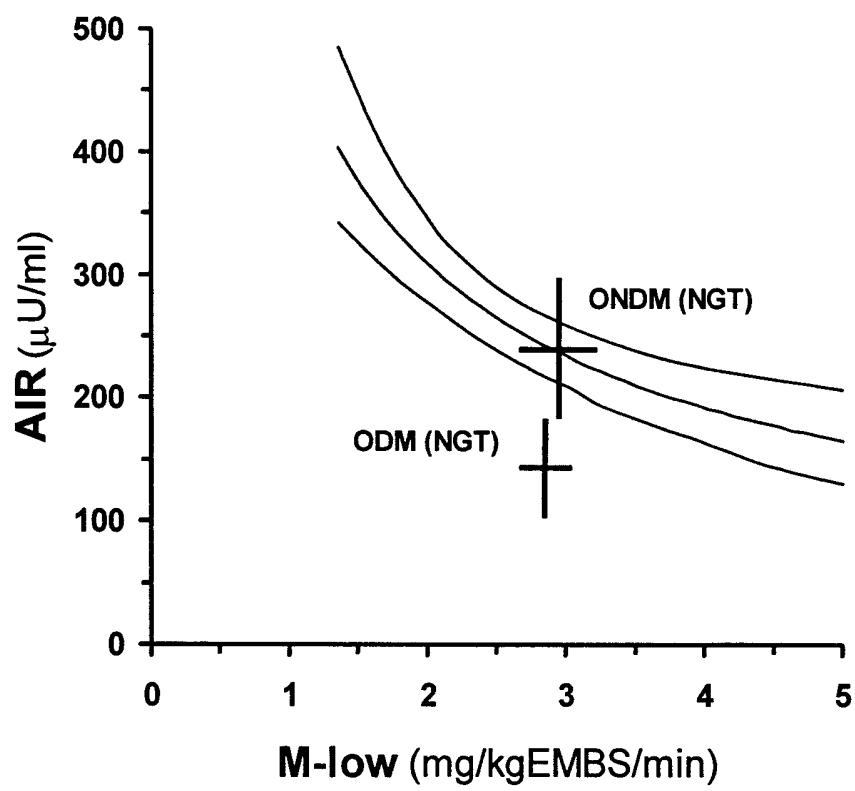

Fig. 6. A Relation between the AIR and insulin action (M-low) in patients with various combinations of glucose intolerance: NFG, normal fasting glucose (fasting glucose $<7 \mathrm{mmol} / \mathrm{l}$ ); NGT, normal glucose tolerance (2-h glucose $<7.8 \mathrm{mmol} / \mathrm{l})$; IFG, impaired fasting glucose (fasting glucose $>6.1$ but $<7$ $\mathrm{mmol} / \mathrm{l}$ ); IGT, impaired glucose tolerance (IGT, 2$\mathrm{h}>7.8 \mathrm{mmol} / \mathrm{l}$ but $<11.1 \mathrm{mmol} / \mathrm{l})$; DFG, diabetic fasting glucose (fasting glucose $>7.1 \mathrm{mmol} / \mathrm{l}$ ) and DGT, diabetic glucose tolerance (2-h glucose $>11.1 \mathrm{mmol} / \mathrm{l})$ [46]. B Relation between the AIR and insulin action (M-low) in the normal glucose tolerant offspring of Pima women who were diabetic during pregnancy (ODM) and a control group of normal glucose tolerant Pimas matched for age, sex and obesity whose mothers were non-diabetic during pregnancy, but subsequently developed diabetes (ONDM). In both graphs, the curved lines represent the mean $\pm 95 \%$ confidence interval for the relation among 277 Pima Indians with normal glucose tolerance tributing to the development of the disease, or whether they are secondary to the metabolic derangements such as mild hyperglycaemia, inherent in these conditions. Consequently, the metabolic characteristics of certain groups of normal glucose tolerant subjects at high risk of diabetes are of considerable interest, both for what they tell us about these groups in particular and for the insights they provide about the pathogenesis of diabetes in general.

Family history of diabetes. A history of diabetes in a first-degree relative substantially increases an individual's risk of developing diabetes. Among Pima Indians, the offspring of parents who developed diabetes before age 45 are at a two- to fourfold increased risk for developing diabetes relative to those whose parents developed diabetes at a later age [6]. A number of studies have found that the offspring of patients with Type II diabetes manifest impairments in first-phase insulin secretion [49-51]. We have recently shown that in addition to impairments in the AIR, insulin secretory responses during graded glucose infusions were lower $(p<0.01)$ in normal glucose tolerant Pima Indians whose parents had early onset diabetes compared to subjects whose parents had late onset diabetes [52].

Gestational diabetes. Women who have had gestational diabetes represent another group at high risk for developing diabetes. Impairments in first-phase insulin secretion have been shown in white and African-American women who had gestational diabetes and were studied several months post-partum after their glucose tolerance had returned to normal [53, 54].

Offspring of diabetic pregnancies. The offspring of women who were diabetic during pregnancy are at high risk for developing impaired glucose tolerance and diabetes [55-58]. Among the Pima Indians, almost half of the children of mothers who were diabetic during pregnancy developed diabetes by age 24 compared to only $9 \%$ of those whose mothers became diabetic after delivery [55]. We have recently shown that the AIR is $40 \%$ lower in the normal glucose tolerant offspring of Pima Indian women who were diabetic during pregnancy than the offspring of women who also developed diabetes at an early age but after the birth of the subject [52]. As with the offspring of parents who developed diabetes at an early age, these subjects had no apparent impairment in insulin action. Thus, although these young adults were still normal glucose tolerant, they clearly lie outside of the normal range, consistent with their high risk of progressing to diabetes (Fig. 6B). 


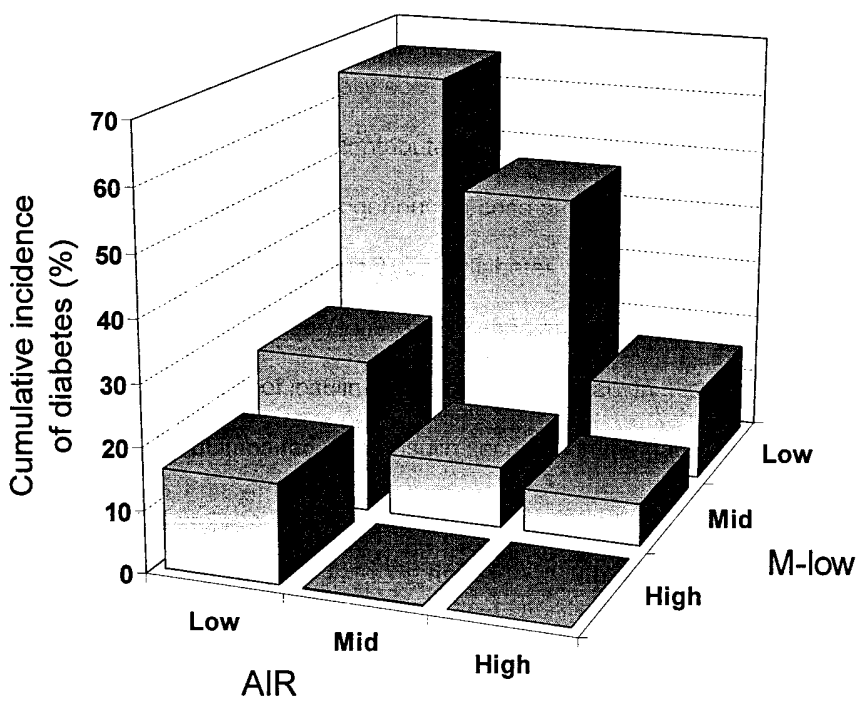

Fig. 7. Cumulative incidence of diabetes among 262 Pima Indians with initially normal glucose tolerance who had measurements of the acute insulin secretory response to intravenous glucose (AIR) and insulin action (M-low) at baseline and who were followed an average of 7 years. Subjects were divided into tertiles of AIR and M-low

\section{Prospective studies: Low early insulin secretion predicts Type II diabetes}

The observation of low first-phase insulin secretion in normal glucose tolerant subjects who are at high risk for diabetes strongly suggests that this finding is not secondary to mild hyperglycaemia and instead, could be a primary metabolic abnormality. However, determination of the metabolic abnormalities that independently predict diabetes requires prospective studies in which insulin secretion and insulin action are measured in non-diabetic subjects who are followedup for several years to ascertain who develops diabetes. Insulin resistance, whether inferred from fasting plasma insulin concentrations $[19,20]$ or directly measured using either the frequently-sampled intravenous glucose tolerance test $[14,15]$ or the hyperinsulinaemic glucose clamp [5], is a consistent predictor of diabetes in various populations but whether defects in early insulin secretion also predict the development of diabetes has been more controversial. Studies in Sweden [11-13] as well as those in the Pima Indians [5] have shown that the acute insulin secretory response to intravenous glucose is an independent predictor of the development of diabetes, particularly when insulin resistance is taken into account. Similarly, a low incremental $30 \mathrm{~min}$ insulin response during oral glucose tolerance testing was found to be a predictor of the development of diabetes in MexicanAmericans, independent of obesity and fasting insulin concentrations [20]. Not all prospective studies however, have shown that low first-phase or early insulin secretion predicts diabetes $[14,15]$.
We have recently re-examined the extent to which AIR and $M$ predict diabetes among Pima Indians (updating studies done in 1993 [5]). Among 262 Pima Indians with initially normal glucose tolerance who underwent measurements of insulin action (Mvalue) and AIR to intravenous glucose, 48 developed diabetes over an average follow-up of 7 years. Insulin resistance and a low AIR each predicted the development of diabetes independently of obesity and independently of one another. The incidence of diabetes was highest among subjects in the lowest tertile of insulin action and insulin secretion (Fig. 7). This group had a cumulative incidence of diabetes of $65 \%$ over 7 years. In contrast, none of the subjects whose insulin action and AIR were in the highest tertile developed diabetes. Subjects with a low AIR but a normal M-value and those with a normal AIR and a low Mvalue had an intermediate risk of developing diabetes. These data indicate that a low AIR is a predictor of developing diabetes, independent of obesity and insulin resistance. Moreover, in contrast to earlier analyses which included fewer subjects and had a shorter duration follow-up [5], both insulin resistance and a low AIR conveyed a similar risk of diabetes.

Although this finding indicates that a low AIR is an independent risk factor for diabetes among persons with normal glucose tolerance, it does not establish whether impaired first-phase insulin secretion predicts worsening of glucose tolerance at each stage of the disease or whether the predictive effects of a low AIR diminish once an individual develops impaired glucose tolerance. To address this question, we have separately analysed the predictive effect of insulin resistance and a low AIR on progression at each stage in the development of diabetes [59]. These analyses indicate that both insulin resistance and a low AIR independently predict progression from normal to impaired glucose tolerance and, separately, from impaired glucose tolerance to diabetes [59].

\section{Longitudinal studies: early insulin secretion declines progressively during the transition from normal glucose tolerance to diabetes}

Although prospective studies have established that both insulin resistance and a low AIR predict diabetes and moreover, predict progression at each stage of the development of the disease among the Pima Indians, these studies do not describe the temporal sequence of events in the metabolic deterioration that ultimately leads to diabetes. Such information can only be obtained from longitudinal studies, in which insulin action and insulin secretion are measured at each stage in the development of diabetes. The Pima Indians of Arizona are an ideal population for studies of this nature because of their high incidence of diabetes and their geographic stability rela- 
tive to other populations. We recently examined the progression to diabetes in 17 Pima Indians who underwent detailed metabolic characterizations on at least 3 occasions, at baseline when they initially had normal glucose tolerance, again when they had impaired glucose tolerance and finally, when they had transitioned to diabetes [47]. Data from these 17 progressors were compared with those obtained in 31 Pima Indians who maintained normal glucose tolerance (non-progressors) and were studied at least 3 times over a similar period of time. During the period of observation, which averaged 5 years in both groups, the progressors gained over $13 \mathrm{~kg}$, which was twofold greater than the average weight gain experienced by the non-progressors. In parallel with this weight gain, insulin action assessed at physiological insulin concentrations declined $14 \%$ during the transition from normal glucose tolerance to diabetes in the progressors and $11 \%$ in the non-progressors. The AIR, which in absolute terms was not different between the groups at baseline, declined $27 \%$ $(p<0.05)$ during the transition from normal to impaired glucose tolerance and another $51 \%$ $(p<0.0001)$ during the transition from impaired glucose tolerance to diabetes in the progressors. In contrast, in the non-progressors, the AIR actually increased by $30 \%$ over the period of observation. The relation between the changes in early insulin secretion and insulin action in both groups is shown in Figure 8A in which the AIR is plotted as a function of insulin action. Although the AIR did not differ between the two groups at baseline, it is evident from this plot that relative to their degree of insulin resistance, early insulin secretion was inappropriately low in the progressors even when they had normal glucose tolerance. In addition to this "primary" defect in early insulin secretion, progression from normal to impaired glucose tolerance and then to diabetes was associated with a steep decline in early insulin secretion but only a modest decline in insulin action. In contrast, in the 31 nonprogressors, early insulin secretion was appropriate for the degree of insulin action at baseline and increased, rather than decreased, in response to a similar decrease in insulin action. Thus, non-progressors were able to maintain normal glucose tolerance by compensating for the development of insulin resistance with increased insulin secretion. These results show the critical role of impairments in early insulin secretion in the pathogenesis of Type II diabetes.

\section{Determinants of first-phase insulin secretion}

Given the evidence that first-phase insulin secretion is important in maintaining normal glucose tolerance, knowledge of the determinants of first-phase insulin secretion is necessary to fully understand the causes of Type II diabetes.
Genetic determinants. Several lines of evidence indicate that first-phase insulin secretion is influenced to a substantial degree by genetic factors. First, the observation that the offspring of parents with Type II diabetes manifest impairments in early insulin secretion well before they develop glucose intolerance suggests that low first-phase insulin secretion is an early and inherited abnormality, rather than a secondary phenomenon [49-51]. Second, several studies have indicated that insulin secretion is highly familial [60-63]. A study estimated the heritability of insulin responses to a glucose infusion to be 0.47 to 0.92 in subjects from 155 nuclear families (96 of which were ascertained through a parent with Type II diabetes) [60]. Among the Pima Indians, analyses of the familiality of insulin responses to an intravenous glucose tolerance test yielded heritability estimates of 0.6 to $0.7[61,62]$. This indicates that approximately two thirds of the variance in first-phase insulin secretion can be attributed to familial factors. Similar estimates of the heritability of first-phase insulin secretion were recently reported in a study of Scandinavian monozygotic and dizygotic twins [63]. Third, there are marked ethnic differences in first-phase insulin secretion. Paradoxically, non-diabetic members of ethnic groups at high risk for diabetes, including Pima Indians [64], Mexican-Americans [65] and AfricanAmericans [65], are characterized by higher firstphase insulin secretory responses than white subjects. These differences in insulin secretion are not attributable to differences in body composition or insulin action and are an early finding, apparent even in subjects with normal glucose tolerance. Of note, various rodent models of diabetes, such as the Zucker diabetic rat, also manifest exaggerated insulin secretory responses before the development of diabetes suggesting that this characteristic could be an early manifestation of a dysregulated beta cell. Finally, although specific genes affecting insulin secretion in Type II diabetes have yet to be identified, recent studies of maturity onset diabetes of the young (MODY) have established that single gene mutations that affect pancreatic beta-cell development or function (hence, insulin secretion) can cause diabetes [66-69].

Acquired determinants. A number of environmental and metabolic conditions can affect first-phase insulin secretion as well.

A defect in first-phase insulin secretion can be acquired from exposure to a diabetic environment in utero. Several studies have indicated that the offspring of diabetic mothers are at increased risk for developing impaired glucose tolerance and Type II diabetes [55-58]. Although not widely studied in humans, among Pima Indians in utero exposure to diabetes resulted in approximately a $40 \%$ impairment in the AIR (Fig. 6B) [52]. The observation that the offspring of rats made mildly diabetic during preg- 
A

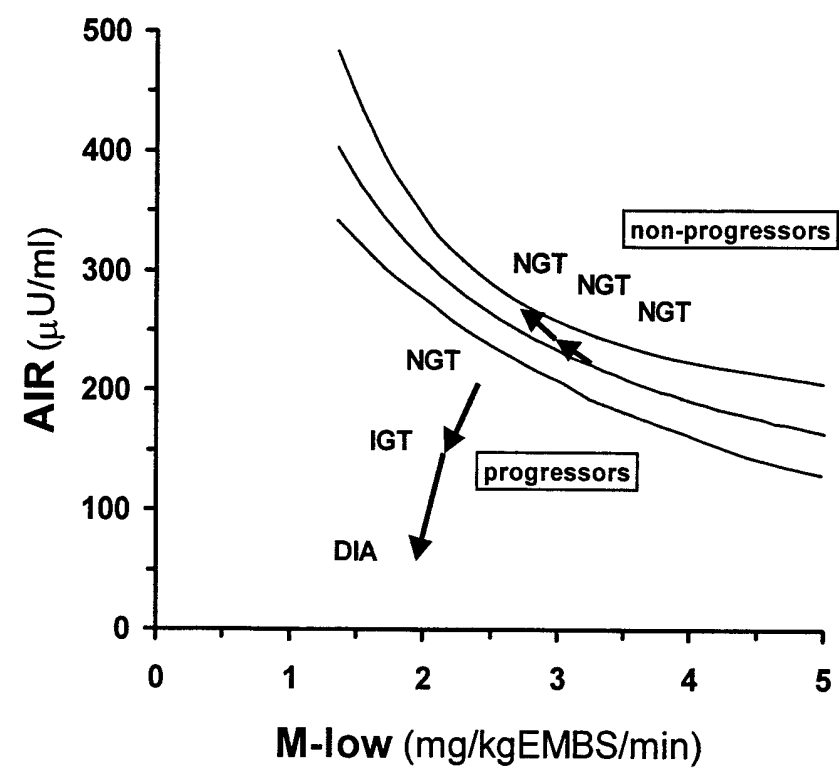

B

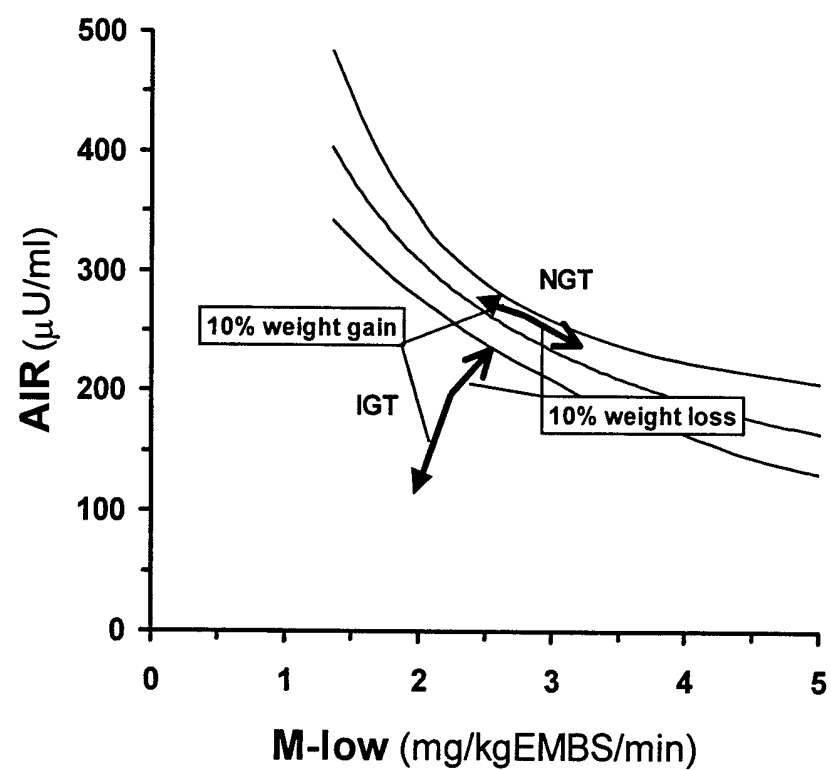

Fig.8. A Relation of the acute insulin secretory response (AIR) to insulin action (M) at each stage of the progression to diabetes in 17 Pima Indians who were initially studied when normal glucose tolerant (NGT) and were restudied when they had impaired glucose tolerance (IGT) and finally after progressing to diabetes (DIA) over an average of 5 years (Progressors). Responses in progressors are compared with those in 31 patients who remained NGT and were studied 3 times over a comparable period of time (Non-progressors). B Effects of a $10 \%$ weight loss or weight gain in Pima Indians with normal glucose tolerance (NGT) and impaired glucose tolerance (IGT). In both graphs, the curved lines represent the mean $\pm 95 \%$ CI for the relation between AIR and M-low among 277 Pima Indians with normal glucose tolerance nancy have reduced insulin secretion in response to glucose [70] has led to the hypothesis that intrauterine exposure to hyperglycaemia during critical periods of fetal development 'programs' the developing pancreas in a way that negatively affects subsequent insulin secretory function.

A diet that is high in saturated fat can have deleterious effects on early insulin secretion. Both Pima Indian and Caucasian adults exposed to a "modern" high fat diet ( $50 \%$ of calories from fat) experienced declines in glucose tolerance associated with impairments in the AIR relative to a "traditional" Pima $\operatorname{diet}(15 \%$ of calories from fat) [71].

While it is widely believed that obesity is associated with insulin hypersecretion, after accounting for the concomitant insulin resistance, impairments in insulin secretion can be observed in obese subjects at high risk for diabetes. It has been shown that among obese non-diabetic subjects with a strong family history of Type II diabetes, the compensatory increase in the acute insulin response to glucose was inadequate for maintaining a normal disposition index $\left(\right.$ AIR $\left.\times S_{I}\right)$ [72]. In addition to the degree of obesity, the pattern of fat deposition could be an important determinant of the acute insulin response. Among white subjects, the AIR correlates with indices of body fat distribution [73]. In contrast, among Pima Indians the AIR is not related $(p=0.66)$ to the waist-to-thigh ratio (an index of body fat distribution) after adjusting for age, sex, percent of body fat and insulin action in multiple regression analyses, nor is it related to the amount of visceral fat [74].

Longitudinally, we have shown that weight gain could lead to a relative impairment in early insulin secretion, especially among subjects with glucose intolerance [75]. In Pima Indians, a 10\% weight gain was associated with an approximately $40 \%$ decrease in the AIR in those with impaired glucose tolerance, but not in those with initially normal glucose tolerance (Fig. 8B). Importantly, a similar amount of weight loss can largely normalize the impairment in the AIR in this group.

The effects of weight gain on acute insulin secretion might be mediated, in part, through the effects of increased non-esterified fatty acids. The relation of insulin secretion to fatty acid availability is complex [76-78]. Non-esterified fatty acids are necessary for normal insulin secretory responses and acutely, free-fatty acids augment glucose-stimulated insulin secretion [76]. Chronic exposure of islets to increased non-esterified fatty acids could, however, inhibit insulin secretion [76]. This could relate to the accumulation of triglycerides (and an increase in intracellular long-chain ocyl-CoA concentrations) within beta cells [77]. Among first degree relatives of persons with Type II diabetes the AIR was shown to be inversely related to fasting free-fatty acid concentrations [79]. Furthermore, infusing lipid and heparin to 
increase circulating non-esterified fatty acids potentiated first-phase insulin secretion in the short term (6 h) but inhibited first-phase insulin secretion if continued for a longer period ( $48 \mathrm{~h}$ ) [80], whereas decreasing non-esterified fatty acids with acipimox augmented insulin secretion [79].

Unger [77] and McGarry [76, 78] who coined the term "lipotoxicity" to describe the detrimental effect of fatty acids on insulin secretion, have proposed that this mechanism could play a critical part in the progressive impairment in insulin secretion that leads to the development of diabetes. This theory is based, in large part, on observations in the Zucker diabetic rat but is also supported by clinical research studies in humans, similar to those described above.

As glucose intolerance develops, chronic hyperglycaemia, while initially potentiating basal and second-phase insulin secretion, can exert detrimental effects on first-phase insulin secretion [81]. This, in turn, can worsen post-prandial glucose tolerance further impairing insulin secretion in a vicious cycle. The plasma glucose concentration at which 'glucotoxicity' becomes an important factor is not known but analysis of the relation of the AIR and fasting glucose concentration suggests that this can occur at fasting glucose concentrations in the "upper normal" range. An important characteristic of glucotoxicity is that it is, at least initially, somewhat reversible. An overnight infusion of insulin to lower blood glucose concentrations into the normal range is associated with an improvement, although not with normalization, of insulin secretion [82]. Similarly, patients with early diabetes who are placed on a hypocaloric diet that normalizes fasting blood glucose concentrations experience a progressive improvement in first-phase insulin secretion over a period of several months [83, 84]. Defects in insulin secretion in hyperglycaemic, $90 \%$ depancreatized rats can be completely prevented by treatment with phlorizin which corrects the hyperglycaemia without direct pancreatic effects [85].

\section{Early insulin secretion as a therapeutic target}

Restoring first-phase insulin secretion improves glucose tolerance. Because loss of early insulin secretion is apparently a critical event in the development of glucose intolerance, the potential therapeutic effects of augmenting early insulin secretion are of interest. The effects of restoring early insulin secretion have been studied in a series of experiments conducted in eight patients with Type II diabetes [86]. The investigators observed that an intravenous insulin infusion given during the first $30 \mathrm{~min}$ of an oral glucose tolerance test to mimic normal early insulin secretory responses markedly improved glucose tolerance and lessened late hyperinsulinaemic responses. Early insulin replacement also caused non-esterified fatty ac- ids and glucagon to decline at a faster rate. The improvement in glucose tolerance was not simply due to the additional insulin, as a continuous infusion of an identical amount of insulin had no effect on the glycaemic response. These investigators also showed that the timing of the insulin infusion was critical, as delaying the infusion by $30 \mathrm{~min}$ (insulin infused from 30-60 min vs 0-30 min) did not improve glucose tolerance. Thus, these studies not only showed the critical importance of early insulin responses in determining the glycaemic response to the meal, they also established the therapeutic potential of augmenting early insulin secretion.

Rapid acting insulin preparations. Intravenous infusion of insulin is obviously not a practical clinical intervention. However, the recent development of rapidacting insulin analogs has provided another means to test the clinical benefit of replacing early insulin secretion in patients with Type II diabetes. The effects of rapid-acting lispro insulin and regular insulin administered before an oral glucose challenge in eight patients with Type II diabetes have been compared [87]. In addition to measuring plasma glucose and insulin responses, endogenous glucose production was measured using an infusion of $\left(3-{ }^{3} \mathrm{H}\right)$-glucose and the rate of appearance of ingested glucose into the circulation was measured with $\left(6-{ }^{13} \mathrm{C}\right)$-glucose. Plasma insulin concentrations peaked earlier with lispro (60 vs $120 \mathrm{~min}$ ), but were lower during the last $3 \mathrm{~h}$ of the study. In spite of a lower late insulin response, the glucose area under the curve was $46 \%$ lower with lispro than with regular insulin. The difference was attributable to a prompter and more complete suppression of endogenous glucose production with lispro than with regular insulin, as rates of appearance of ingested glucose did not differ between treatments. Pulmonary administration of regular insulin, which is in advanced clinical development, also has a pharmacodynamic profile suggesting that it could have utility in replacing the early insulin response and thus controlling postprandial hyperglycaemia [88].

GLP-1. Drugs targeting the glucagon-like peptide (GLP-1) receptor might also prove efficacious in augmenting endogenous early insulin secretion and thus controlling post-prandial hyperglycaemia. GLP-1 is a potent, naturally occurring hormone that increases insulin secretion in a glucose-dependent manner. In six patients with Type II diabetes, subcutaneous injections of GLP-1 improved insulin responses during the $30 \mathrm{~min}$ immediately after ingestion of a standard test meal compared to placebo [89]. This resulted in a $58 \%$ decrease in the glucose area under the curve. In a separate study, an overnight infusion of GLP-1 was shown to improve first and second-phase insulin secretion during a hyperglycaemic glucose clamp in eight patients with Type II diabetes [90]. 
Oral agents. Several studies have shown that sulfonlyureas augment first-phase insulin secretion [91-95]. This effect however, does not appear specific for first-phase insulin secretion, as basal and secondphase insulin secretion are increased as well. The tendency to enhance basal and second-phase insulin secretion could contribute to the propensity of these drugs to cause hypoglycaemia and could, in the long term, contribute to the loss of clinical efficacy of these agents.

In recent years, several new non-sulfonylurea insulin secretagogues have been developed. Pharmacologic characterization of these agents has suggested some important differences in the pattern of insulin secretion promoted by these and older agents [96-98]. The potential for newer agents to increase early insulin secretion and thereby lower prandial glucose excursions, without causing a concomitant increase in basal or second phase insulin secretion, suggests that they could offer advantages over first and second generation sulfonylureas by causing less hypoglycaemia and, potentially, preserving beta cell function.

\section{Summary}

Early insulin secretion is a critical metabolic event that efficiently switches metabolism from the fasting state, in which endogenous glucose production and non-insulin mediated glucose disposal predominate, to the prandial state in which endogenous glucose production is suppressed and insulin-mediated glucose disposal predominates. Both genetic and acquired factors can lead to impairments in early insulin secretion. As early insulin secretion declines, glucose intolerance develops. The development of post-prandial hyperglycaemia, characteristic of patients with impaired glucose tolerance, could contribute to worsening insulin secretion through the mechanism of glucotoxicity. Eventually, the defect in insulin secretion reaches a critical threshold, endogenous glucose production becomes dysregulated and frank hyperglycaemia develops. Enhancing early insulin responses improves glucose tolerance in patients with Type II diabetes. Thus, strategies to augment early insulin secretion represent a novel approach to improving glycaemic control in patients with Type II diabetes mellitus and could even prove useful in preventing the metabolic decompensation characteristic of the progression to diabetes.

Acknowledgements. The authors thank the members and leaders of the Gila River Indian Community without whose cooperation and support these studies would not have been possible. We are indebted to Dr. C. Bogardus whose vision and leadership has ensured the success of this project. We gratefully acknowledge the many scientists and physicians who have contributed their time and energy to the research over the years.
Finally, we thank Mr. M. Milner, Ms. C. Massengill and the nurses of the Clinical Research Unit for the care of the patients in this study, Dr. A. Salbe and the staff of the metabolic kitchen and the Clinical Diabetes and Nutrition Section technical staff for assisting in the analyses.

\section{References}

1. Pratley RE, Weyer C, Bogardus C (2000) Metabolic abnormalities in the development of type 2 diabetes mellitus. In: LeRoith D, Taylor SI (eds) Diabetes mellitus: a fundamental and clinical text. Lippincott, Philadelphia, pp 548-557

2. DeFronzo RA (1988) Lilly Lecture 1987. The triumvirate: B-cell, muscle liver. A collusion responsible for type 2 diabetes. Diabetes 37: 667-687

3. Porte D Jr (1991) Banting Lecture 1990. $\beta$-cells in type II diabetes mellitus. Diabetes 40: 166-180

4. Byrne MM, Sturis J, Cavaghan M, O'Meara NM, Polonsky KS (2000) Insulin secretion in humans. Physiological regulation and alterations in disease states. In: LeRoith D, Taylor SI (eds) Diabetes mellitus: a fundamental and clinical text. Lippincott, Philadelphia, pp 105-114

5. Lillioja S, Mott DM, Spraul M et al. (1993) Insulin resistance and insulin secretory dysfunction as precursors of non-insulin-dependent diabetes mellitus. Prospective studies of Pima Indians. N Engl J Med 329: 1988-1992

6. Knowler WC, Pettitt DJ, Saad MF, Bennett PH (1990) Diabetes mellitus in the Pima Indians: incidence risk factors and pathogenesis. Diabetes Metab Rev 6: 1-27

7. Grodsky GM (2000) Kinetics of insulin secretion. Underlying metabolic events. In: LeRoith D, Taylor SI (eds) Diabetes mellitus: a fundamental and clinical text. Lippincott, Philadelphia, pp 2-11

8. Daniel S, Noda M, Straub SG, Sharp GW (1999) Identification of the docked granule pool responsible for first-phase of glucose-stimulated insulin secretion. Diabetes 48: $1686-1690$

9. DeFronzo RA, Tobin JD, Andres R (1979) Glucose clamp technique: a method for quantifying insulin secretion and resistance. Am J Physiol 237: E214-E223

10. Pratley RE, Hagberg JM, Dengel DR, Rogus EM, Muller DC, Goldberg AP (2000) Aerobic exercise training-induced reductions in abdominal fat and glucose-stimulated insulin responses in middle-aged and older men. $\mathrm{J}$ Am Geriatr Soc 48: 1055-1061

11. Efendic S, Luft R, Wajngot A (1984) Aspects of the pathogenesis of type 2 diabetes. Endocr Rev 5: 395-410

12. Skarfors ET, Selinus KI, Lithell HO (1991) Risk factors for developing non-insulin dependent diabetes: a 10 year follow up of men in Uppsala. BMJ 303: 755-760

13. Lundgren H, Bengtsson C, Blohm G, Lapidus L, Waldenström J (1990) Fasting serum insulin concentration and early insulin response as risk determinants for developing diabetes. Diabet Med 7: 407-413

14. Warram JH, Martin BC, Krolewski AS, Soeldner JS, Kahn RC (1990) Slow glucose removal rate and hyperinsulinemia precede the development of type II diabetes in the offspring of diabetic parents. Ann Intern Med 113: 909-915

15. Martin BC, Warram JH, Krolewski AS, Bergman RN, Soeldner JS, Kahn RC (1992) Role of glucose and insulin resistance in development of type 2 diabetes mellitus; results of a 25-year follow-up study. Lancet 340: 925-929

16. Charles MA, Fontbonne A, Thibult N, Warnet J-M, Rosselin GE, Eschwege E (1991) Risk factors for type 2 diabe- 
tes in white population: Paris prospective study. Diabetes 40: 796-799

17. Sicree RA, Zimmet PZ, King HOM, Coventry JS (1987) Plasma insulin response among Nauruans: prediction of deterioration in glucose tolerance over 6 yr. Diabetes 36: 179-186

18. Kadowaki T, Miyake Y, Hagura R et al. (1984) Risk factors for worsening to diabetes in subjects with impaired glucose tolerance. Diabetologia 26: 44-49

19. Saad MF, Knowler WC, Pettitt DJ, Nelson RG, Charles MA, Bennett PH (1991) A two-step model for development of non-insulin-dependent diabetes mellitus. Am J Med 90: 229-235

20. Haffner SM, Miettinen H, Gaskill SP, Stern MP (1995) Decreased insulin secretion and increased insulin resistance are independently related to the 7-year risk of NIDDM in Mexican-Americans. Diabetes 44: 1386-1391

21. Hanson RL, Pratley RE, Bogardus C et al. (2000) Evaluation of simple indices of insulin sensitivity and insulin secretion for use in epidemiologic studies. Am J Epidemiol 151: 190-198

22. Vranic M, Fono P, Kovacevic N, Lin BJ (1971) Glucose kinetics and fatty acids in dogs on matched insulin infusion after glucose load. Metabolism 10: 954-967

23. Calles-Escandon J, Robbins DC (1987) Loss of early phase of insulin release in humans impairs glucose tolerance and blunts thermic effect of glucose. Diabetes 36: 1167-1172

24. Luzi L, DeFronzo RA (1989) Effect of loss of first-phase insulin secretion on hepatic glucose production and tissue glucose disposal in humans. Am J Physiol 257: E241-E246

25. Elahi D, Meneilly GS, Minaker KL, Andersen DK, Rowe JW (1989) Escape of hepatic glucose production during hyperglycemic glucose clamp. Am J Physiol 257: E704-E711

26. Castillo C, Bogardus C, Bergman R, Thuillez P, Lillioja S (1994) Interstitial insulin concentrations determine glucose uptake rates but not insulin resistance in lean and obese men. J Clin Invest 83: 10-16

27. Getty L, Hamilton-Wessler M, Adler M, Dea MK, Bergman RN (1999) Biphasic insulin secretion during intravenous glucose tolerance test promotes optimal interstitial insulin profile. Diabetes 47: 1941-1947

28. Bergman RN (1997) New concepts in extracellular signaling for insulin action: the single gateway hypothesis. Recent Prog Horm Res 52: 359-385

29. Rebrin K, Steil GM, Mittelman SD, Bergman RN (1996) Causal linkage between insulin suppression of lipolysis and suppression of liver glucose output in dogs. J Clin Invest 98: 741-749

30. Kahn SE, Prigeon RL, McCulloch DK et al. (1993) Quantification of the relationship between insulin sensitivity and beta-cell function in humans. Evidence for a hyperbolic function. Diabetes 42: 1663-1672

31. Yalow RS, Berson SA (1960) Plasma insulin concentrations in nondiabetics and early diabetic subjects. Diabetes 9: 254

32. Reaven G, Miller R (1968) Study of the relationship between glucose and insulin responses to an oral glucose load in man. Diabetes 17: 560-569

33. Welborn TA, Stenhouse NS, Johnstone CG (1969) Factors determining serum-insulin response in a population sample. Diabetologia 5: 263-266

34. Cerasi E, Luft R (1967) The plasma insulin response to glucose infusion in healthy subjects and in diabetes mellitus. Acta Endocrinol 55: 278-304

35. Brunzell JD, Robertson RP, Lerner RL et al. (1976) Relationships between fasting plasma glucose levels and insulin secretion during intravenous glucose tolerance tests. J Clin Endocrinol Metab 42: 222-229
36. Meneilly GS, Dawson K, Tessier D (1993) Alterations in glucose metabolism in the elderly patient with diabetes. Diabetes Care 16: 1241-1248

37. Bourey RE, Kohrt WM, Kirwan JP, Staten MA, King DS, Holloszy JO (1993) Relationship between glucose tolerance and glucose stimulated insulin response in 65-yearolds. J Gerontol 48: M122-M127

38. The expert committee on the diagnosis and classification of diabetes mellitus (1999) Report of the expert committee on the diagnosis and classification of Diabetes mellitus. Diabetes Care 22: S5-S19

39. Kelley D, Mokan M, Veneman T (1994) Impaired postprandial glucose utilization in non-insulin-dependent diabetes mellitus. Metabolism 43: 1549-1557

40. Ericksson J, Franssila-Kallunki A, Ekstrand A et al. (1989) Early metabolic defects in persons at increased risk for non-insulin dependent diabetes mellitus. N Engl J Med 321: 337-343

41. Cerasi E, Luft R, Effendic S (1972) Decreased sensitivity of the pancreatic beta cells to glucose in prediabetic and diabetic subjects. A glucose dose-response study. Diabetes 21: 224-234

42. Yoneda H, Ikagami H, Yamamoto Y et al. (1992) Analysis of early phase insulin responses in non-obese subjects with mild glucose intolerance. Diabetes Care15: 1517-1521

43. Pimenta W (1996) Insulin secretion and insulin deficiency in people with impaired glucose tolerance. Diabet Med 13: S33-S36

44. Matsumoto K, Miyake S, Yano M et al. (1997) Glucose tolerance, insulin secretion, and insulin sensitivity in nonobese and obese Japanese subjects. Diabetes Care 20: $1562-1568$

45. Reaven GM, Olefsky JM (1977) Relationship between heterogeneity of insulin responses and insulin resistance in normal subjects and patients with chemical diabetes. Diabetologia 13: 201-206

46. Reaven GM, Hollenbeck CB, Chen YDI (1989) Relationship between glucose tolerance, insulin secretion, and insulin resistance in non-obese individuals with varying degrees of glucose tolerance. Diabetologia 32: 53-55

47. Weyer C, Bogardus C, Mott DM, Pratley RE (1999) The natural history of insulin secretory dysfunction and insulin resistance in the pathogenesis of type 2 diabetes mellitus. J Clin Invest 104: 787-794

48. Weyer C, Bogardus C, Pratley RE (1999) Metabolic characteristics of individuals with impaired fasting glucose and/or impaired glucose tolerance. Diabetes 48: 2197-2203

49. O'Rahilly SP, Nugent Z, Rudenski AS et al. (1986) Betacell dysfunction, rather than insulin insensitivity, is the primary defect in familial type 2 diabetes. Lancet ii: 360-364

50. Pimenta W, Korytkowski M, Mitrakou A et al. (1995) Pancreatic beta-cell dysfunction as the primary genetic lesion in NIDDM. Evidence from studies in normal glucose-tolerant individuals with a first-degree NIDDM relative. JAMA 273: $1855-1861$

51. Thorburn AW, Proietto J (1999) Peripheral tissue glucose uptake is not reduced after an oral glucose tolerance load in Southern Italian subjects at risk for developing non-insulin-dependent diabetes mellitus. Metabolism 48: 80-85

52. Gautier J-F, Wilson C, Weyer C et al. (2001) Low acute insulin secretory responses in adult offspring of persons with early onset Type II diabetes. Diabetes (in press)

53. Ward WK, Johnston CL, Beard JC, Benedetti TJ, Porte D Jr (1985) Abnormalities of B-cell function, insulin action and fat distribution in women with histories of gestational diabetes: relationship to obesity. J Clin Endocrinol Metab 62: 1043-1045 
54. Osei K, Gaillard TR, Schuster DP (1998) History of gestational diabetes leads to distinct metabolic alterations in non-diabetic African-American women with a parental history of type 2 diabetes. Diabetes Care 21: 1250-1257

55. Pettitt DJ, Aleck KA, Baird HR, Carraher MJ, Bennett PH, Knowler WC (1988) Congenital susceptibility to NIDDM. Role of intrauterine environment. Diabetes 37: 622-628

56. Aerts L, Holemans K, Van Assche FA (1990) Maternal diabetes during pregnancy: consequences for the offspring. Diabetes Metab Rev 6: 147-167

57. Silverman BL, Metzger BE, Cho NH, Loeb CA (1995) Impaired glucose tolerance in adolescent offspring of diabetic mothers. Relationship to fetal hyperinsulinism. Diabetes Care 18: 611-617

58. Plagemann A, Harder T, Kohlhoff R, Rohde W, Dorner G (1997) Glucose tolerance and insulin secretion in children of mothers with pregestational IDDM or gestational diabetes. Diabetologia 40: 1094-1100

59. Weyer C, Tataranni PA, Bogardus C, Pratley RE (2001) Insulin resistance and low early phase insulin secretion predict the progression from impaired glucose tolerance (IGT) to diabetes in Pima Indians. Diabetes Care 24: 89-94

60. Iselius L, Lindsten J, Morton NE et al. (1982) Evidence for an autosomal recessive gene regulating the persistence of the insulin response to glucose in man. Clin Genet 22: 180-194

61. Janssen RC, Bogardus C, Takeda J, Knowler WC, Thompson DB (1994) Linkage analysis of acute insulin secretion with GLUT2 and glucokinase in Pima Indians and the identification of a missense mutation in GLUT2. Diabetes 43: $558-563$

62. Sakul H, Pratley R, Cardon L, Ravussin E, Mott D, Bogardus C (1997) Familiality of physical and metabolic characteristics that predict the development of non-insulin-dependent diabetes mellitus in Pima Indians. Am J Hum Genet 60: 651-656

63. Lehtovirta M, Kaprio J, Forsblom C, Ericksson J, Tuomilehto J, Groop L (2000) Insulin sensitivity and secretion in monozygotic and dizygotic twins. Diabetologia 43: 285-293

64. Lillioja S, Nyomba BL, Saad MF et al. (1991) Exaggerated early insulin release and insulin resistance in a diabetesprone population: a metabolic comparison of Pima Indians and Caucasians. J Clin Endocrinol Metab 73: 866-876

65. Haffner SM, D’Agostino R, Saad MF et al. (1996) Increased insulin resistance and insulin secretion in non-diabetic African-Americans and Hispanics compared with non-Hispanic whites: The Insulin Resistance in Atherosclerosis Study. Diabetes 45: 742-748

66. Froguelle P, Zouali H, Bionnet N et al. (1993) Familial hyperglycemia due to mutations in glucokinase: definition of a new subtype of non-insulin-dependent (type 2) diabetes mellitus. N Engl J Med 328: 697-702

67. Yamagata K, Oda N, Kaisaki PJ et al. (1996) Mutations in the hepatocyte nuclear factor-1-alpha gene in maturity onset diabetes of the young (MODY3). Nature 384: 455-458

68. Yamagata K, Furata H, Oda N et al. (1996) Mutations in the hepatocyte nuclear factor-4-alpha gene in maturity onset diabetes of the young (MODY1) Nature 384: 458-460

69. Stoffers DA, Ferrer J, Clarke WL, Habener JF (1997) Early-onset type-II diabetes mellitus (MODY4) linked to IPF1. Nat Genet 17: 138-139

70. Aerts L, Sodoyez-Goffaux F, Sodoyez JC, Malaisse WJ, Van Assche FA (1988) The diabetic intrauterine milieu has a long-lasting effect on insulin secretion by B cells and on insulin uptake by target tissues. Am J Obstet Gynecol 159: $1287-1292$
71. Swinburn BA, Boyce VL, Bergman RN, Howard BV, Bogardus C (1991) Deterioration in carbohydrate metabolism and lipoprotein metabolism induced by a modern, high fat diet in Pima Indians and Caucasians. J Clin Endocrinol Metab 73: 156-165

72. Elbein SC, Wegner K, Kahn SE (2000) Reduced beta-cell compensation to the insulin resistance associated with obesity in members of caucasian familial type 2 diabetic kindreds. Diabetes Care 23: 221-227

73. Clausen JO, Borch-Johnsen K, Ibsen H et al. (1996) Insulin sensitivity index, acute insulin response, and glucose effectiveness in a population-based sample of 380 young healthy Caucasians. J Clin Invest 98: 1195-1209

74. Gautier JF, Milner MR, Elam E, Chen K, Ravussin E, Pratley RE (1999) Visceral adipose tissue is not increased in Pima Indians compared with equally obese Caucasians and is not related to insulin action or secretion. Diabetologia 42: 28-34

75. Weyer C, Hanson K, Bogardus C, Pratley RE (2000) Longterm changes in insulin action and insulin secretion associated with gain, loss, regain and maintenance of body weight. Diabetologia 43: 36-46

76. McGarry JD, Dobbins RL (1999) Fatty acids, lipotoxicity and insulin secretion. Diabetologia 42: 128-138

77. Unger RH (1995) Lipotoxicity in the pathogenesis of obesity-dependent NIDDM. Genetic and clinical implications. Diabetes 44: 863-870

78. McGarry JD (1994) Disordered metabolism in diabetes: Have we underestimated the fat component? J Cell Biochem 558: 29-38

79. Paolisso G, Gambardella A, Amato L et al. (1995) Opposite effects of short- and long-term fatty acid infusion on insulin secretion in healthy subjects. Diabetologia 38: 1295-1299

80. Paolisso G, Tagliamonte MR, Rizzo MR et al. (1998) Lowering fatty acids potentiates acute insulin response in first degree relatives of people with type II diabetes. Diabetologia 41: 1127-1132

81. Leahy JL, Cooper HE, Deal DA, Weir GC (1986) Chronic hyperglycemia is associated with impaired glucose influence on insulin secretion: a study in normal rats using chronic in vivo glucose infusions. J Clin Invest 77: 908-915

82. Laedtke T, Kjems L, Porksen N et al. (2000) Overnight inhibition of insulin secretion restores pulsatility and proinsulin/insulin ratio in type 2 diabetes. Am J Physiol 279: E520-E528

83. Savage PJ, Bennion LJ, Flock EV et al. (1979) Diet-induced improvement of abnormalities in insulin and glucagon secretion and in insulin receptor binding in diabetes mellitus. J Clin Endocrinol Metab 48: 999-1007

84. Savage PJ, Bennion LJ, Bennett PH (1979) Normalization of insulin and glucagon secretion in ketosis-resistant diabetes mellitus with prolonged diet therapy. J Clin Endocrinol Metab 49: 830-833

85. Rossetti L, Shulman GI, Zawalich W, DeFronzo RA (1987) Effect of chronic hyperglycemia on insulin secretion in partially pancreatectomized rats. J Clin Invest 80: 1037-1044

86. Bruce DG, Chisholm DJ, Storlien LH, Kraegen EW (1988) Physiological importance of deficiency in early prandial insulin secretion in non-insulin-dependent diabetes. Diabetes 37: 736-744

87. Bruttomesso D, Pianta A, Mari A et al. (1999) Restoration of early rise in plasma insulin levels improves the glucose tolerance in type 2 diabetic patients. Diabetes 48: 99-105

88. Heinemann L, Klappoth W, Rave K, Hompesch B, Linkeschowa R, Heise T. (2000) Intra-individual variability of 
the metabolic effect of inhaled insulin together with an absorption enhancer. Diabetes Care 23: 1343-1347

89. Todd JF, Edwards CM, Ghatei MA, Mather HM, Bloom SR (1998) Subcutaneous glucagon-like peptide-1 improves postprandial glycaemic control over a 3 week period in patients with early type 2 diabetes. Clin Sci (Colch) 95: 325-329

90. Rachman J, Gribble FM, Barrow BA, Levy JC, Buchanan KD, Turner RC (1996) Normalization of insulin responses to glucose by overnight infusion of glucagon-like peptide 1 (7-36) amide in patients with NIDDM. Diabetes 45: 1524-1530

91. Pfeifer MA, Halter JB, Beard JC, Porte D Jr (1981) Differential effects of tolbutamide on first and second phase insulin secretion in noninsulin-dependent diabetes mellitus. J Clin Endocrinol Metab 53: 1256-1262

92. Groop L, Luzi L, Melander A et al. (1987) Different effects of glyburide and glipizide on insulin secretion and hepatic glucose production in normal and NIDDM subjects. Diabetes 36: $1320-1328$

93. van Haeften TW, Veneman TF, Gerich JE, van der Veen EA (1991) Influence of gliclazide on glucose-stimulated insulin release in man. Metabolism 40: 751-755
94. Groop LC, Ratheiser K, Luzi L et al. (1991) Effect of sulfonylurea on glucose-stimulated insulin secretion in healthy and non-insulin dependent diabetic subjects: a dose-response study. Acta Diabetol 28: 162-168

95. Ligtenberg JJ, Venker CE, Sluiter WJ, Reitsma WD, Van Haeften TW (1997) Effect of glibenclamide on insulin release at moderate and high blood glucose levels in normal man. Eur J Clin Invest 27: 685-689

96. Owens DR, Ismail I, Luzio SD, Bayer T (2000) Increased prandial insulin secretion after administration of a single preprandial oral dose of repaglinide in patients with type 2 diabetes. Diabetes Care 23: 518-523

97. Whitelaw DC, Clark PM, Smith JM, Nattrass M (2000) Effects of the new oral hypoglycaemic agent nateglinide on insulin secretion in type 2 diabetes mellitus. Diabet Med 17: $225-229$

98. Hanefield M, Dickinson S, Bouter KP, Guitard C (2000) Rapid and short acting mealtime insulin secretion with nateglinide controls both prandial and mean glycemia. Diabetes Care 23: 202-207 